\title{
Response latency and accuracy in visual word recogniton
}

\author{
CRIT SCHIEPERS \\ Instituut voor Perceptie Onderzoek, Den Dolech 2, Eindhoven, The Netherlands
}

\begin{abstract}
In a single visual word recognition experiment, the effects of (1) eccentricity of presentation, (2) word length, and (3) word frequency were investigated. The stimuli used were Dutch nouns in two frequency classes of about 15 and 150.10-6; word length varied from 1 to 10 ; eccentricity varied from -4 to $+4 \mathrm{deg}$. The response quality and response latency of 11 subjects were measured. For the correct responses, recognition scores decreased and response latencies increased with eccentricity; both showed asymmetrical curves in the visual field. It is argued that word length proper affects neither the probability of correct responses nor latency. A clear word frequency effect was established. The eccentricity of presentation is considered as the determinant of the amount of available information, thus directly influencing accuracy and latency. The linear relationship between accuracy and latency is a major finding. A word recognition scheme is offered which incorporates (1) activation, (2) decision, and (3) speech. The time relations between incoming retinal information and response decision, leading to an extra $400 \mathrm{msec}$ for incorrect as compared with correct responses, are discussed. Word recognition in reading is examined, together with the impact of the present experimental results on information flow in successive eye fixations, eye movement control, and eye-voice span.
\end{abstract}

In the cognitive act of reading, several processes are involved: information is extracted from the text, processed, recognized, assigned a meaning, and, sometimes, uttered overtly. We are mainly interested in the visual reading processes, particularly in the cues for recognition. In printed text, words clearly form visual entities; in addition, words are emphasized in teaching people to read. We therefore work on the assumption that words are relevant units in visual reading processes.

Both perceptual and linguistic factors contribute in word recognition (Neisser, 1967; Gibson \& Levin, 1975). An important line of research at the Institute for Perception Research has been the specification of perceptual factors in single words in relation to the stimulus configuration (Bouma, 1971, 1973; Schiepers, 1976a, 1976b, 1978). The linguistic aspects of word recognition, on the other hand, are brought about the reader's knowledge of the language. Generally established linguistic factors affecting word recognition are, for example, word frequency (Broadbent, 1967; Rosenzweig \& Postman, 1958), word meaning and redundancy by contrasting words vs. pseudowords vs. nonwords (Kolers, 1970; Wheeler, 1970), familiarity (Bouwhuis, 1979), and context (Morton, 1969). In our previous experiments (Schiepers, 1976b, 1976c), word frequency and

The active support of Dr. D. Bouwhuis in the preparation of this paper was highly appreciated. I am also indebted to Dr. H. Bouma for many stimulating discussions. The research was supported by the Netherlands Organization for the Advancement of Pure Research (ZWO). distributional constraints in the language were found to have only a minor influence. Probably, our experimental conditions, which imitate reading fixations as closely as possible, were responsible for a high transfer of stimulus information, thus giving prevalence to perceptual factors. In the experiments mentioned (Bouma, 1971, 1973; Schiepers, 1976a, 1976b, 1978), only accuracy measurements were used, indicating that the aspects of the word recognition process investigated were fairly static. Reading, however, is a dynamic process, and in order to throw light on the complexity of the recognition processes, dynamic aspects must be studied as well. Accuracy measurements only reveal the final result of the recognition process. The amount of available information, the attention of the reader, the accessibility of words in the lexicon, competing responses, etc. possibly also affect the time in which recognition is completed; that is probably longer under difficult (experimental) circumstances. A time measure such as response latency is thought to be a suitable indicator of these underlying processes. We assume that differences in latency reflect different rates of processing at some stage in the pathway, that is, depending on available attributes, the accessibility of words, and the decision mechanism.

The elements of words are letters, which are quite differently affected by retinal eccentricity than are the words they compose. With increasing eccentricity, recognition performance worsens. Accuracy measurements on single letters do not show left-right visual field differences (Bouma, 1971), whereas in word recognition clearly asymmetrical curves around the 
fovea are found (Mishkin \& Forgays, 1952). Recognition of letters in strings also yields asymmetrical curves (Schiepers, 1978). Latency measurements show an increase with eccentricity, and for letter recognition they also supply symmetrical curves (Eriksen \& Schultz, 1977; Lefton \& Haber, 1974). In a pilot experiment (Schiepers, Note 4), response latencies in word recognition showed an absence of visual field asymmetry, although there was a substantial left-right difference in recognition scores. This disagreement between the course of scores and latencies calls for further clarification.

In the experiment to be reported, the eccentricity of presentation, the length of the words, and the frequency of their occurrence in the language were varied. The simultaneous effect of these variables on recognition performance and response latency were the subject of this study.

\section{METHOD}

\section{Terminology}

For the abbreviations and symbols used in this paper, see Table 1.

\section{Subjects}

The subjects were 11 university students ( 9 male, 2 female), who had participated in earlier experiments. They were aged between 19 and 26 years; they had adequate (corrected) vision, with foveal acuity ranging from 1.25 to 2 , and were right-handed.

\section{Materials}

The stimuli were Dutch nouns, plus the only one-letter word in Dutch and eight two-letter words (adverbs and pronouns). There were two classes with a frequency of occurrence in print: (1) between 10 and 20 per million (LF) and (2) between 100 and 200 per million (HF), according to the lists of de la Court (Linschoten, Note 1) and Uit den Bogaart (1975). Word lengths varied from 1 to 10 letters. Eccentricities of presentation were: foveal, $\pm 1, \pm 2, \pm 3$, and $\pm 4 \mathrm{deg}$. For every eccentricity, a separate stimulus block was prepared containing 44 LF and $45 \mathrm{HF}$ words; the distribution of stimulus lengths was: one one-letter word ( $l=1$, ' $u$ ', HF) and, for both frequency classes, four two-letter words $(l=2)$ and five for each length from 3 to $10(3 \leqslant l \leqslant 10)$.

The words were typed on white paper with an IBM-72 typewriter. The typeface was Courier with a height of $1.95 \mathrm{~mm}$ for

Table 1

Terminology Used

\begin{tabular}{ll}
\hline Symbol & \multicolumn{1}{c}{ Definition } \\
\hline$\phi$ & eccentricity of presentation \\
$\phi_{\text {nom }}$ & nominal eccentricity* \\
$l$ & word length, number of letters \\
$\mathrm{p}$ & recognition'score $\dagger$ \\
LT & response latency $\dagger$ \\
LVF & left visual field $(\phi<0 \mathrm{deg})$ \\
RVF & right visual field $(\phi>0 \mathrm{deg})$ \\
WF & word frequency \\
LF & low frequency, 10-20 per million \\
HF & high frequency, 100-200 per million \\
\hline
\end{tabular}

*Distance of fixation to the nearest letter of stimulus.

†Index denoting response category; indices: $c=$ correct, $i=$ incorrect, ill = illegible. short letters and of $2.70 \mathrm{~mm}$ for ascenders and descenders; the letter spacing was $2.55 \mathrm{~mm}$. The words in a stimulus block were randomized. The distance from the fovea to the first letter of a word in the RVF or the last in the LVF was kept constant; this is defined here as the nominal eccentricity: $\phi_{\text {nom }}$. The foveal stimuli, however, were typed across the center of the visual field. For parafoveal stimuli, each word was presented once to the left and once to the right of fixation; in one session, each word appeared only once. A randomized block design was used for subjects and eccentricities.

\section{Apparatus}

The stimuli were presented in a two-channel tachistoscope. The luminance was about $150 \mathrm{~cd} / \mathrm{m}^{2}$; the exposure duration was $100 \mathrm{msec}$; the viewing distance was $570 \mathrm{~mm}$, where $10 \mathrm{~mm}$ (four letters) corresponds to 1 deg of visual angle; vision was binocular. A " +" was used as the fixation mark. A blank field of about $300 \times 300 \mathrm{~mm}$, illuminated with white light, was replaced by a congruent field containing the stimulus word for $100 \mathrm{msec}$, which is below the latency of an eye saccade. In each session, the stimuli were presented at one eccentricity to the left and right of fixation in order to aid the maintenance of fixation. The subject initiated an exposure by pressing a button. An infrared video system was used to record the subject's eye for the purpose of checking proper fixation. A voice key was used to measure the response latencies. An electronic timer measured the interval from the onset of the stimulus till the first above-threshold signal of the voice key, which was adjusted for every subject to ensure proper reaction to voiceless consonants and hissing sounds. The experiments of Schröder (Note 2) showed that latencies of the voice key deviate by about $20 \mathrm{msec}$ round the mean.

\section{Procedure}

The subjects were asked to report the word they had recognized and were permitted to respond "illegible." They were asked to speak at a constant level. The subjects were not informed of the aim of the experiment. After two training sessions, the experiment proper was started.

The measures used in the experiment were accuracy and latency. Responses were categorized as: (1) correct, (2) incorrect, or (3) illegible. Responses were categorized "illegible" because: (1) the subject gave this answer, (2) the voice key failed, (3) the latency exceeded the 3-sec interval, or (4) the subject hesitated and did not directly respond with a word. The latencies were measured for correct and incorrect responses, those for the "illegible" responses were discarded.

\section{RESULTS AND DISCUSSION}

There were 979 foveal responses, of which 970 $(99.1 \%)$ were correct, $2(.2 \%)$ incorrect, and 7 $(.7 \%)$ illegible. The mean correct response latency was $649 \mathrm{msec}$ with a standard deviation of $107 \mathrm{msec}$. The total number of parafoveal responses was 7,832 , of which 3,734 (47.7\%) were correct, 2,653 (33.9\%) incorrect, and 1,445 (18.4\%) illegible. The "illegible" responses mainly involved the longer words and the larger eccentricities, and twice as many "illegible" responses occurred in the LVF as in the RVF. On average, correct parafoveal responses took $871 \mathrm{msec}$ and incorrect responses, $1,316 \mathrm{msec}$. For each subject, the data of parafoveal stimuli were divided into the first and second half; averaged over all subjects, the results yielded the following differences between the two halves: for recognition scores, 


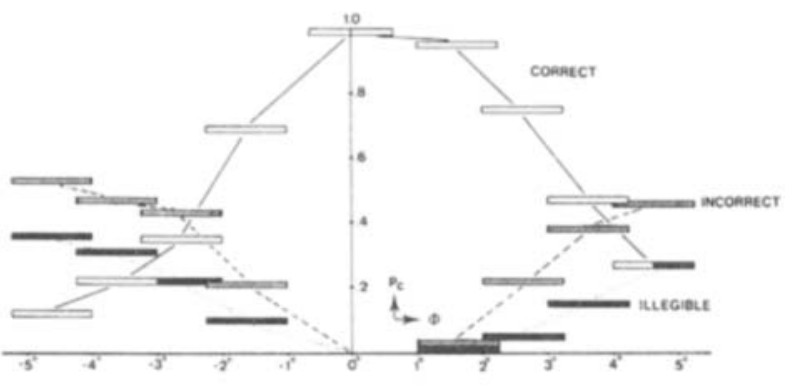

Figure 1. Proportions correct (white), incorrect (hatched), and illegible (black), averaged over all subjects, word length, and word frequency as a function of the eccentricity. Note the left-right asymmetry.

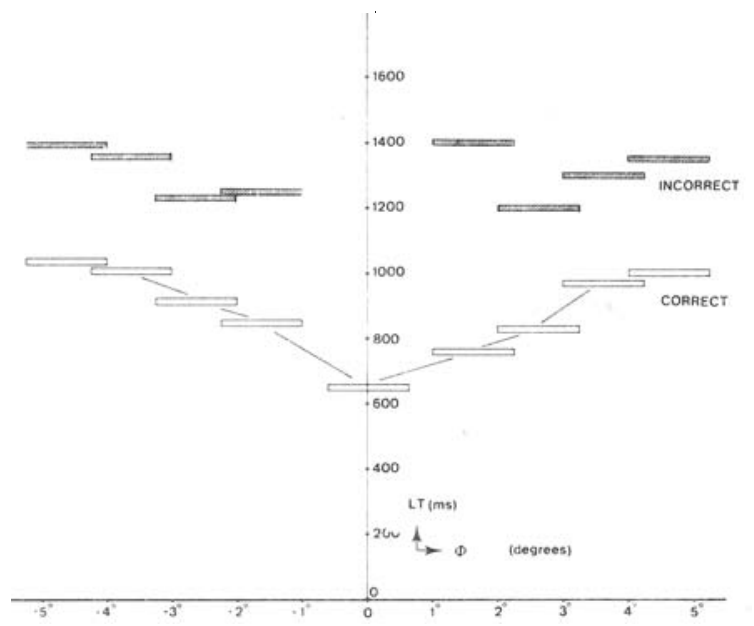

Figure 2. Response latencies of correct (white) and incorrect (hatched) responses averaged over all subjects, word length, and word frequency in relation to eccentricity. $\mathbf{L T}_{\mathbf{i}}$ for $\phi=+1 \mathrm{deg}$ contains only 26 data. Note the asymmetrical $L_{c}$ curve, not present for $\mathbf{L T} \mathbf{T}_{\mathbf{i}}$.

$46.9 \% \quad$ vs. $48.4 \% \quad$ (correct), $34.2 \%$ vs. $33.5 \%$ (incorrect), $18.9 \%$ vs. $18.1 \%$ (illegible); and for latencies, 886 vs. $856 \mathrm{msec}$ (correct) and 1,339 vs. $1,292 \mathrm{msec}$ (incorrect). This indicates that the influence of training was small.

The recognition scores in the three response categories averaged over WF, lengths, and subjects are depicted in Figure 1. As expected for Dutch words (Bouma, 1973), word recognition is better in the RVF. The present correct scores are approximately $10 \%$ lower than those previously given (Schiepers, 1976b). The extra restrictions imposed because of latency measurements are the obvious cause of this decrease, leading to $10 \%$ more illegible responses. Just as in the earlier experiments, the curve of correct scores seems symmetrical around $\phi=+1 / 2 \mathrm{deg}$.

The latencies of correct and incorrect responses averaged over WF, lengths, and subjects are given in Figure 2 as a function of the eccentricity. The latencies of correct responses increase in the parafovea by about $90 \mathrm{msec} / \mathrm{deg}^{1}$; they show significant left-right differences for $\phi_{\text {nom }}= \pm 1 \mathrm{deg}$ and $\pm 2 \mathrm{deg}$ $(p<.05)$. The latencies of incorrect responses also increase with eccentricity, but they have a smaller slope, of about $50 \mathrm{msec} / \mathrm{deg}$. The data point $\mathrm{LT}_{\mathrm{i}}$ at $\phi_{\text {nom }}=+1 \mathrm{deg}$ contains only 26 responses, and the conspicuously longer latency is mainly caused by responses to LF words of length 10 (see also Figure 3).

The mean, standard deviation, and number of responses for the pooled data at every eccentricity are given in Table 2. With increasing $\phi$, the standard deviation increases as well. Analogously to Schiepers (Note 4) and for reasons explained below, a "modified $z$ score" was computed according to the formula: $\mathrm{z}=$ mean latency/standard deviation. The resultant values are also given in Table 2 .

Except for the foveal stimuli, the modified $\mathrm{z}$ scores are not significantly different $(p>.05, t$ test). This may be interpreted as meaning that the processes underlying both correct and incorrect responses are highly similar over eccentricity. Less available information (e.g., producing an incorrect response) causes longer processing times that lead to longer latencies and to more of the "noise" originating from the recognition system in the final latency distribution. This "noise" is expressed by a constant increment of the standard deviation, suggesting additive processes.

Table 2

Response Latencies (LT) and Standard Deviations (SD) in Milliseconds

\begin{tabular}{lrrrrrrrrr}
\hline$\phi$ & $-4^{\circ}$ & $-3^{\circ}$ & $-2^{\circ}$ & $-1^{\circ}$ & Foveal & $1^{\circ}$ & $2^{\circ}$ & $3^{\circ}$ \\
\hline & & & & & Correct & & & \\
& & & & & & \\
LT & 1040 & 1010 & 915 & 850 & 650 & 765 & 825 & 970 \\
SD & 315 & 300 & 275 & 240 & 110 & 205 & 220 & 300 & 270 \\
N & 109 & 217 & 344 & 674 & 970 & 933 & 732 & 462 & 263 \\
z & 3.30 & 3.37 & 3.33 & 3.54 & $5.91^{*}$ & 3.73 & 3.75 & 3.23 & 3.70 \\
& & & & & Incorrect & & & & \\
LT & 1390 & 1355 & 1240 & 1260 & & 1400 & 1200 & 1300 & 1350 \\
SD & 410 & 420 & 410 & 415 & & 525 & 435 & 450 & 410 \\
N & 517 & 459 & 420 & 204 & & 26 & 204 & 370 & 453 \\
z & 3.39 & 3.23 & 3.02 & 3.04 & & 2.67 & 2.76 & 2.89 & 3.29 \\
\hline
\end{tabular}

Note $-N=$ number of responses; $z=$ modified $z$ score $(L T / S D)$.

*Significantly different $(p<.05, t$ test). 

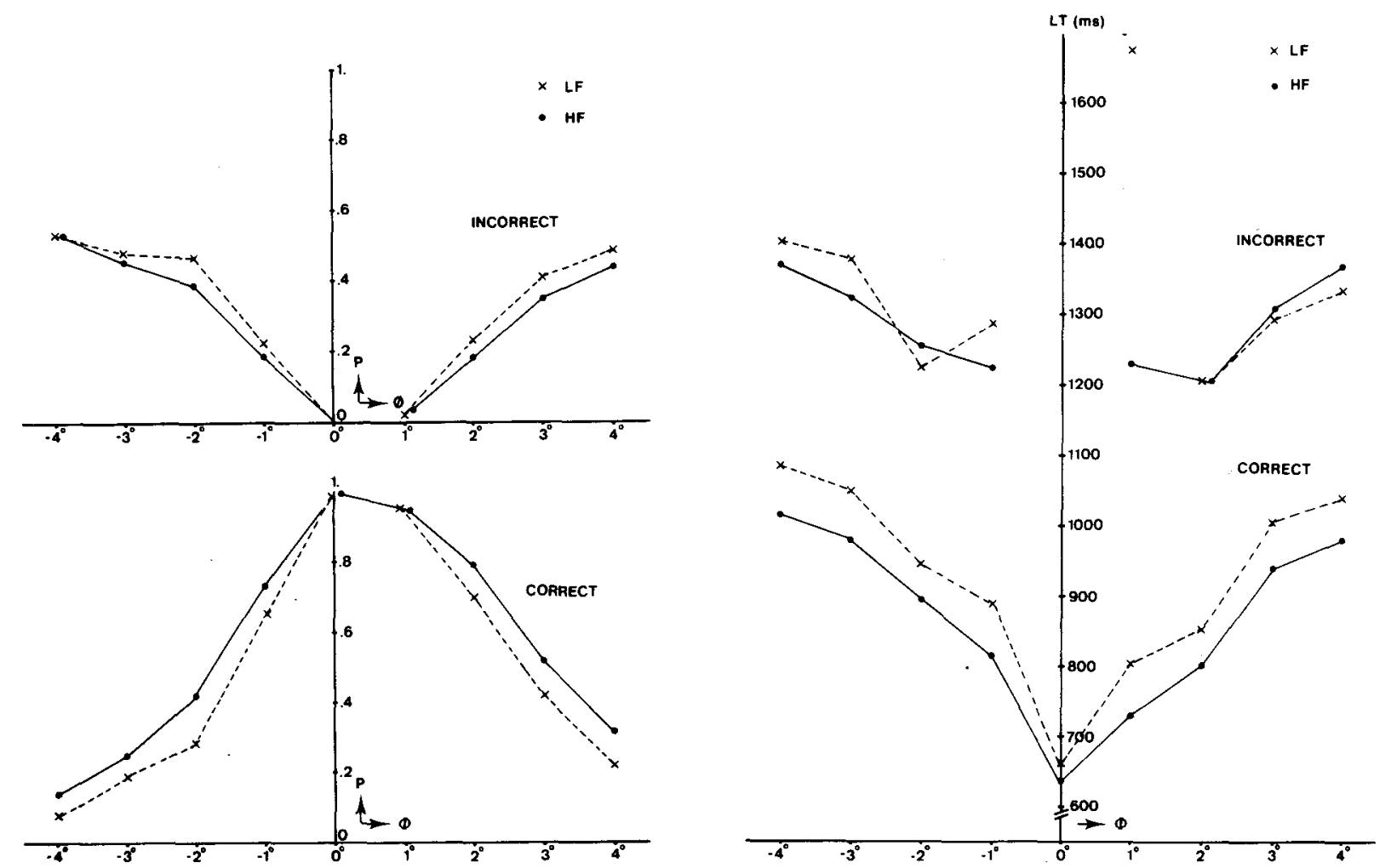

Figure 3. Proportions correct and incorrect and corresponding response latencies for the two frequency classes: LF ( $x$ ) and HF ( $\bullet$. Averages over subjects and word lengths. $N=10$ for incorrect responses to $L F$ words at $\phi=+1$ deg. The word-frequency effect is consistent for all eccentricities.

\section{Word Frequency}

Figure 3 presents the recognition scores and latencies for the two frequency classes in relation to eccentricity averaged over lengths and subjects. In the case of correct responses, the WF effect is clearly expressed and consistent in the parafovea: HF words score approximately $8 \%$ higher than LF words.

The latencies of correct responses quite nicely show a consistent time course over the visual field. The WF effect is significant (sign test), being somewhat smaller in the fovea $(25 \mathrm{msec})$ than in the parafovea (on average $65 \pm 15 \mathrm{msec}$ ). WF was not chosen too low, in order to avoid the possibility that the subject might not know the word. In the latter case, familiarity differences would be measured instead of WF effects. Familiarity can have much greater effects than WF (Bouwhuis, 1979). The effects of WF are smaller in central than in parafoveal vision, supporting Broadbent's statement (1967) that WF effects are overruled when the stimulus information is high. The modest, but consistent, WF effect suggests that, in our experiment, perceptual factors were of greater prominence than linguistic ones.

The incorrect responses to LF and HF stimuli do not show significantly different latencies; this tallies with Morton's model (1969), which states that WF is not a property of the stimulus configuration.

\section{Word Length}

The gross effect of word length on scores and latencies is shown in Figure 4; the data are averaged over WF and subjects in the LVF and RVF. The proportion of correct responses decreases with increasing word length, while the proportion of incorrect responses increases, reaching a plateau at about $l=5$ ("illegible" responses make up for the difference). In the RVF, latencies of correct responses $L T_{c}$ are little affected by word length; in the $L V F$, however, a dependence is manifest. $L T_{i}$ values clearly show an influence of word length, both in the LVF and RVF. However, recognition of long words decreases sharply with eccentricity. This is not discernible in Figure 4, since averaging over eccentricities masks such an influence of different word lengths. A detailed presentation of response latencies with regard to word length, word frequency, and eccentricity would produce unreliable data because of the relatively small number of responses. Instead, we averaged over WF and subjects and carried out, for every eccentricity, linear regression analyses on 

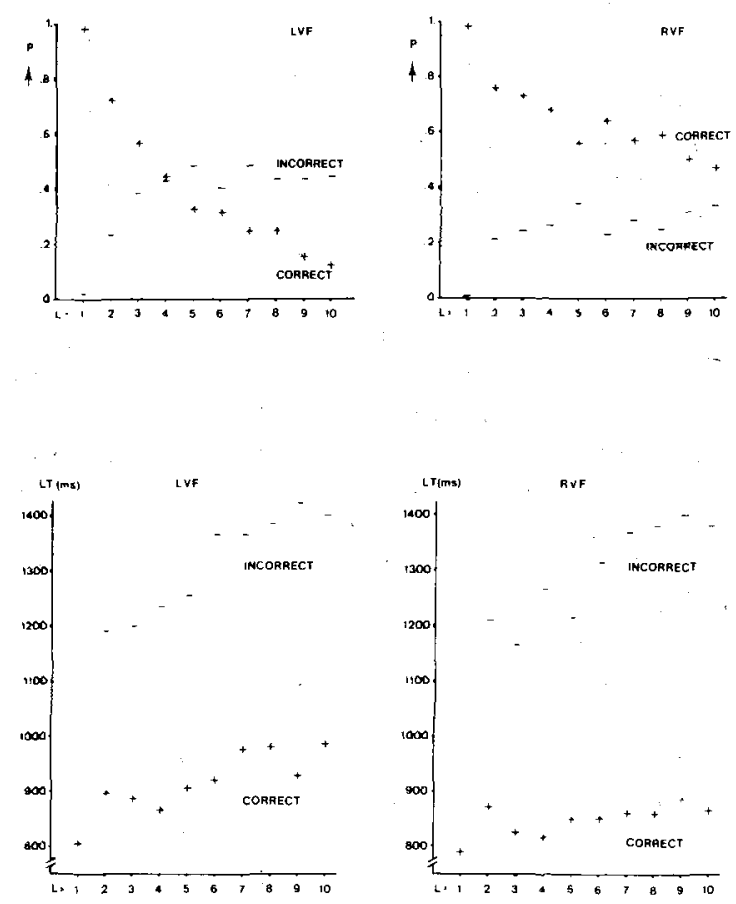

Figure 4. Proportions and response latencies for correct and incorrect responses in relation to word length for the two half fields. Averages over subjects, eccentricity, and word frequency. The gross effect of word length on $\mathrm{LT}_{\mathrm{c}}$ is more pronounced in the LVF than in the RVF; the effect on $\mathrm{LT}_{\mathbf{i}}$, however, seems equal.

both proportions and latencies as a function of word length: $\mathrm{p}=\mathrm{a}+\mathrm{b} \cdot \mathrm{l}, \mathrm{LT}=\mathrm{a}^{\prime}+\mathrm{b}^{\prime} \cdot l$; Table 3 gives the slopes $b, b^{\prime}$ for the various situations.

In the fovea, neither $\mathrm{p}_{\mathrm{c}}$ nor $\mathrm{LT}_{\mathrm{c}}$ are influenced at all by word length, as is to be expected from the clear and detailed vision in this area. In the parafovea, proportions correct decrease almost linearly with increasing word length; except for $\phi_{\text {nom }}=+1$ and $+2 \mathrm{deg}$, the slopes are not significantly different from each other $(p>.05$, McNemar, 1963). The observed values of $p_{c}$ cover a very wide range in our experiment, and a linear measure is not an appro- priate form in which to display the data. We therefore transformed the proportions $p_{c}$ to logit $p_{c}=$ $\log _{e}\left[p_{c} /\left(1-p_{c}\right)\right]$ (cf. Morton, 1969). This assumes logistically distributed "noise" in the data, and was chosen for convenience. In practice, it is equivalent to a normal distribution.

The logit transformation can be seen to provide a good linear relation to word length with equal slopes for the various retinal eccentricities despite the very large range of $p_{c}$ involved (Figure 5).

The information decrease with increasing word length is assumed to reflect the adverse interactions between letters which impede parafoveal recognition (Bouma, 1970; Woodworth, 1938), depending on the number of elements (Eriksen \& Hoffman, 1972; Estes, 1975) or the number of letters (Bouma, 1973; Schiepers, 1976b).

LVF data are generally on a lower level than RVF data (Figure 5), and therefore more information is extracted from or available in the RVF. This strongly supports Bouma's (1978) proposals on visual interference. Bouma's (1973) earlier suggestion that visual interference has a larger spatial extent in the LVF than in the RVF has to be abandoned, for the slopes are equal in Figure 5.

Table 3 shows that the slopes of the correct latencies as a function of word length are roughly constant in the parafovea (except $\phi=+1 \mathrm{deg}$ ).

$\mathrm{LT}_{\mathrm{i}}$ values show a more discerning increase with $l$. These LT-l relations at different eccentricities may be visualized as straight lines with equal slopes but different intercepts. Fortunately, latency measurements do not suffer from ceiling effects, so we tried to make an optimal estimate of the slope for correct as well as incorrect responses. We therefore shifted the raw data vertically to the same $\phi_{\text {nom. }}$. This meant a translation of latencies along the time axis that amounted to $89 \mathrm{msec}$ for every degree for $\mathrm{LT}_{\mathrm{c}}$ and $51 \mathrm{msec}$ for every degree for $L T_{i}$, as may be estimated from Figure 2 and Table 3 . Only data points with $N>10$ were included. On these translated data, linear regres-

Table 3

Slopes of the Linear Regression Lines $p=a+b$. i and LT $=a^{\prime}+b^{\prime}$. l

\begin{tabular}{|c|c|c|c|c|c|c|c|c|c|}
\hline$\phi_{\text {nom }}$ & $-4^{\circ}$ & $-\mathbf{3}^{\circ}$ & $-2^{\circ}$ & $-1^{\circ}$ & Foveal & $1^{\circ}$ & $2^{\circ}$ & $3^{\circ}$ & $4^{\circ}$ \\
\hline & \multicolumn{9}{|c|}{ Correct } \\
\hline $\begin{array}{l}\text { Slope (Proportion/Letter) } \\
\text { Mean } \mathrm{p}_{\mathrm{c}} \\
\text { SD }\end{array}$ & & $\begin{array}{l}-.08 \\
.29 \dagger \\
.22\end{array}$ & $\begin{array}{l}-.10 \\
.39 \dagger \\
.23\end{array}$ & $\begin{array}{r}-.07 \\
.69 \\
.20\end{array}$ & $\begin{array}{l}.00^{*} \\
.99 \\
.01\end{array}$ & $\begin{array}{l}-.01^{*} \\
.95 \\
.04\end{array}$ & $\begin{array}{l}-.03^{*} \\
.75 \\
.10\end{array}$ & $\begin{array}{r}-.06 \\
.47 \\
.18\end{array}$ & $\begin{array}{l}-.04 \\
.29 \dagger \\
.12\end{array}$ \\
\hline $\begin{array}{l}\text { Slope (Msec/Letter) } \\
\text { Mean } \mathrm{LT}_{\mathbf{c}}(\text { Msec) } \\
\text { SD }\end{array}$ & & $\begin{array}{c}24 \\
1046 \dagger \\
89\end{array}$ & $\begin{array}{l}25 \\
963 \dagger \\
113\end{array}$ & $\begin{array}{r}24 \\
871 \\
71\end{array}$ & $\begin{array}{c}0^{*} \\
649 \\
12\end{array}$ & $\begin{array}{c}1^{*} \\
769 \\
40\end{array}$ & $\begin{array}{r}13 \\
830 \\
43\end{array}$ & $\begin{array}{r}22 \\
944 \\
82\end{array}$ & $\begin{array}{c}15 \\
1029 \dagger \\
57\end{array}$ \\
\hline SD & \multicolumn{9}{|c|}{ Incorrect } \\
\hline $\begin{array}{l}\text { Slope (Msec/Letter) } \\
\text { Mean } \mathrm{LT}_{\mathbf{i}} \text { (Msec) } \\
\text { SD }\end{array}$ & $\begin{array}{r}23 \\
1396 \\
96\end{array}$ & $\begin{array}{r}39 \\
1346 \\
137\end{array}$ & $\begin{array}{c}52^{*} \\
1235 \dagger \\
140\end{array}$ & $\begin{array}{c}46 \\
1254 \dagger \\
112\end{array}$ & & & $\begin{array}{c}32 \\
1191 \dagger \\
111\end{array}$ & $\begin{array}{r}37 \\
1298 \\
118\end{array}$ & $\begin{array}{r}27 \\
1351 \\
88\end{array}$ \\
\hline
\end{tabular}

Note-Mean proportions and latencies obtained from this analysis are also given for the various eccentricities. $*$ Significantly different from all other elements in the same row, as shown by the t test on regression slope difference $p>.05$ (McNemar, 1963$)$. tNumber of data points smaller than cight (normally nine). 


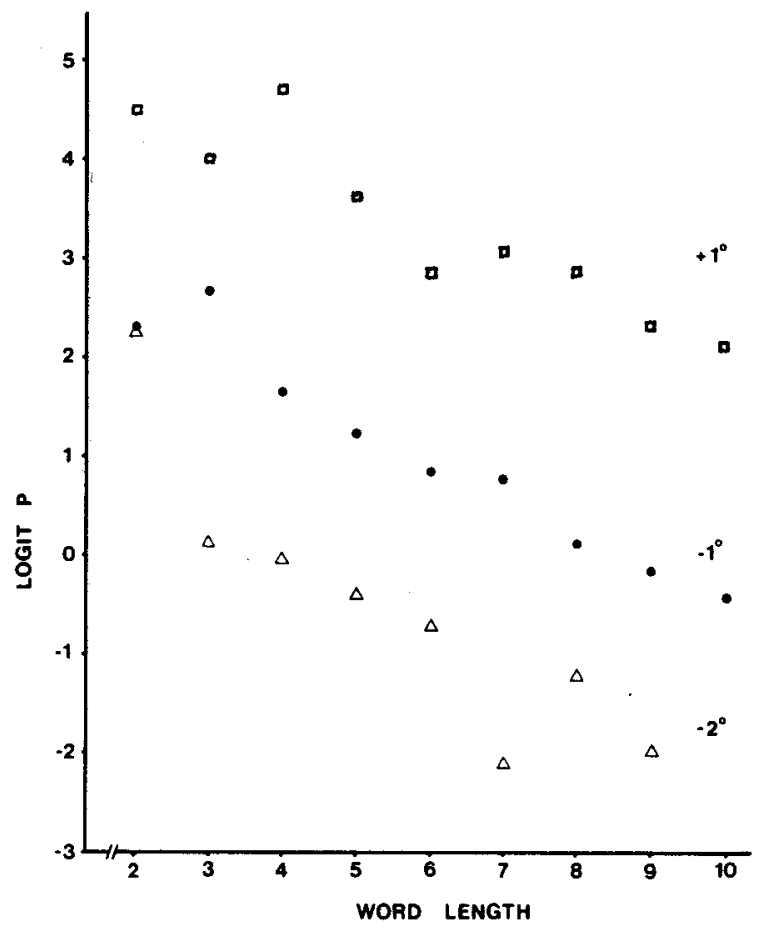

Figure 5. Transformed proportions correct: $\operatorname{logit} p=\log _{\mathrm{e}}$ [p/(1-p)] as a function of word length for three eccentricities (for reasons of clarity). The amount of visual information decreases linearly with word length. More information is available close to the fovea and in the RVF compared with the LVF.

sion analyses were carried out. Thus, the optimal estimate of the slope amounted to $20 \mathrm{msec} / \mathrm{letter}$ for $\mathrm{LT}_{\mathrm{c}}$ and to $34 \mathrm{msec} /$ letter for $\mathrm{LT}_{\mathrm{i}}$.

In the experiment, we kept constant the distance between fixation mark and the nearest letter, defined as $\phi_{\text {nom. }}$. If we wish to consider the distance between fixation mark and the middle of the word, we have to add half a letter's distance $(1 / 8 \mathrm{deg})$ for every letter increase $(1 / 4 \mathrm{deg})$ in word length. For correct responses, Figure 2 and Table 2 give a slope of $89 \mathrm{msec} / \mathrm{deg}$, corresponding to $11 \mathrm{msec} /$ letter length increment. The response latencies also include speech programming. Eriksen, Pollack, \& Montague (1970) found an increment of $11 \mathrm{msec}$ per extra syllable for vocalizing English words. Using this figure for Dutch ( 1 syllable $=$ about $2 \frac{1}{2}$ letters) accounts for another $4 \mathrm{msec} / \mathrm{letter}$. On the basis of these results, a slope of $15 \mathrm{msec} /$ letter is expected, which does not differ significantly from the estimated slope of $20 \mathrm{msec} / \mathrm{letter}$ (Table 3) in our data ( $p>.05$, McNemar, 1963).

Thus, from a visual point of view, word length proper does not affect probability correct or response latency; rather, the eccentricity of presentation determines the amount of visual information, which is directly expressed in recognition performance. In experiments, two aspects are important: (1) the amount of information available in the visual system, and (2) the information necessary for completing recog- nition. Comparison of foveal and parafoveal recognition illustrates this distinction, parafoveal data probably reflecting the necessary information. More stimulus information is available in central vision, so foveal exposure does not show length effects. In parafoveal vision, the center of long words has to be presented at the same distance from the fovea as the center of short words in order to yield equal amounts of visual information (logit $p_{c}$, i.e., $p_{c}$, constant).

Rosenzweig and Postman (1958) showed that word length affected only low-frequency words, and that recognition threshold increased with word length. This result was corroborated by Doggett and Richards (1975)-word length influences the recognition threshold if words are unfamiliar, but not if they are familiar (on average, $50 \mathrm{msec}$ for a 10-letter word of WF $1-5 /$ million). For conditions like ours, exposure duration $100 \mathrm{msec}$ and WF $>10 /$ million, word length effects are not expected, as was established.

Terry, Samuels, and LaBerge (1976) did not find the slightest hint of an increase in latency with word length up to 6 letters. Johnson (1975) also did not find that it had any effect, whereas Cosky (1976) did for word lengths up to 8 letters. These experiments used foveal presentation and long exposure, so abundant information is available. The word-length influence found by Cosky is most likely explained by his procedure of having the subject start to read as soon as possible.

For incorrect responses, the latency shows a clearcut effect of word length, namely $34 \mathrm{msec} /$ letter. After the same correction as for correct responses, $24 \mathrm{msec} /$ letter remains. A "simple" explanation for this length dependence might be that, with increasing word length, there are a growing number of alternatives in the lexicon. The available information then has to be distributed over more accessed alternatives, leading to longer waiting times for the central processor to assemble enough activation to respond. Moreover, the accessibility of words varies greatly (Bouwhuis, 1979).

\section{Accuracy, Latency, and Word Length}

Thus far, we have presented separate graphs for either scores or latencies. Figure 1 showed that correct scores drop from the fovea outwards and at the same time the response latencies increase (Figure 2). A similar correspondence holds for the incorrect responses. This $\phi$ dependence indicates a direct relation between scores and latencies. In an attempt to unravel the different contributions, $\mathrm{p}, \mathrm{LT}$, and $l$ were plotted in one graph. Neglecting $l=1\left(\mathrm{p}_{\mathrm{c}}\right.$ always equals 1), it proves that all parafoveal data points fall in a slanting plane parallel to the $l$-axis; this result is schematically represented in Figure 6. A straight line may be drawn through data points at a certain eccentricity, and this can be visualized as the secant of the slanting data plane and a section plane perpen- 


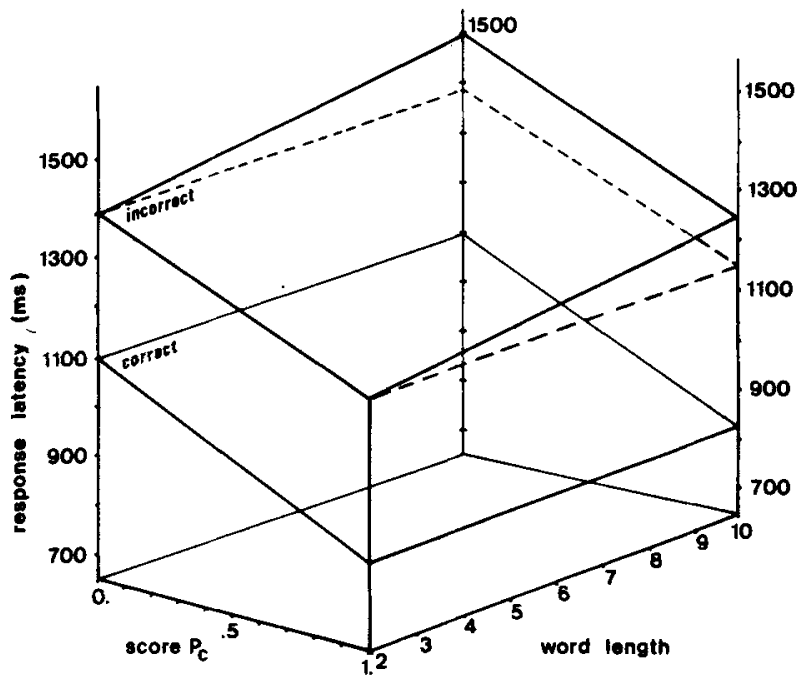

Figure 6. Schematic representation of the data planes of all correct and incorrect responses averaged over subjects and word frequency. Three variables: word length, accuracy, and latency. The $l$-axis is parallel to the data plane "correct," whereas the data plane "incorrect" is at a small angle to the "correct" one (indicated by the broken line) that amounts to about $15 \mathrm{msec} /$ letter. When the proportion correct is constant, all word lengths have the same response latency.

dicular to the bottom (p-l) plane. The various computed regression lines (Table 3, Figure 7) are the projections of this secant onto the p-l, LT- $l$, and LT-p planes.

For correct responses, it is then clear from Figure 6 that, for $\phi_{\text {nom }}=+1 \mathrm{deg}$, the secant is almost parallel to the $l$-axis $\left(\mathrm{p}_{\mathrm{c}}\right.$ nearly always $\left.=1\right)$ and the projections result in small or zero slopes in the p-l and LT-l planes. For larger eccentricities, the secant rotates around $l=1, \mathrm{p}_{\mathrm{c}}=1$. Because of the oblique data plane, the slopes of the projections increase from zero to a maximum of about $6 \% /$ letter in the $\mathrm{p}-l$ plane and $25 \mathrm{msec} / \mathrm{letter}$ in the LT-l plane. For still larger eccentricities, the slopes remain constant. The implication of Figure 6 is that when equal amounts of information are picked up (constant $p_{c}$, see Figure 5), the LT-l relationship has a zero slope, i.e., word length does not affect processing time. When less information is available, the processing times become proportionally longer, i.e., the recognition system acts as a linear integrator.

Since the plane for correct responses is perpendicular to the LT-p plane, the LT-p relationship may be investigated with data averaged over word lengths. The incorrect responses may also be situated in a plane, but this time with a positive angle to the l-axis (Figure 6); the projections onto the LT-l plane yield larger slopes than those obtained for correct responses. A serious difficulty exists with regard to these incorrect responses: because of an increasing number of "illegible" responses as the stimulus information decreases, the scores do not become higher than
$55 \%$. Raw data for $p_{i}$ overestimate the slope in the LT-p relation because of the shrunk p-axis. Neglect of "illegible" responses (assuming $p_{i}=1-p_{c}$ ) results in the slope being underestimated. Therefore, we transformed the proportions of correct and incorrect responses to $p_{c}^{*}+p_{i}^{*}=1$. The results are given in Figure 7.

The regression lines read:

$$
\begin{aligned}
\mathrm{LT}_{\mathrm{c}} & =-355 \mathrm{p}_{\mathrm{c}}^{*}+1,115 \\
\mathrm{LT}_{\mathrm{i}} & =255\left(1-\mathrm{p}_{\mathrm{c}}^{*}\right)+1,170 \\
& =255 \mathrm{p}_{\mathrm{i}}^{*}+1,170 .
\end{aligned}
$$

The slopes of the two regression lines do not differ significantly ( $p>.05$, McNemar, 1963). A comparison of the slopes for raw and transformed data

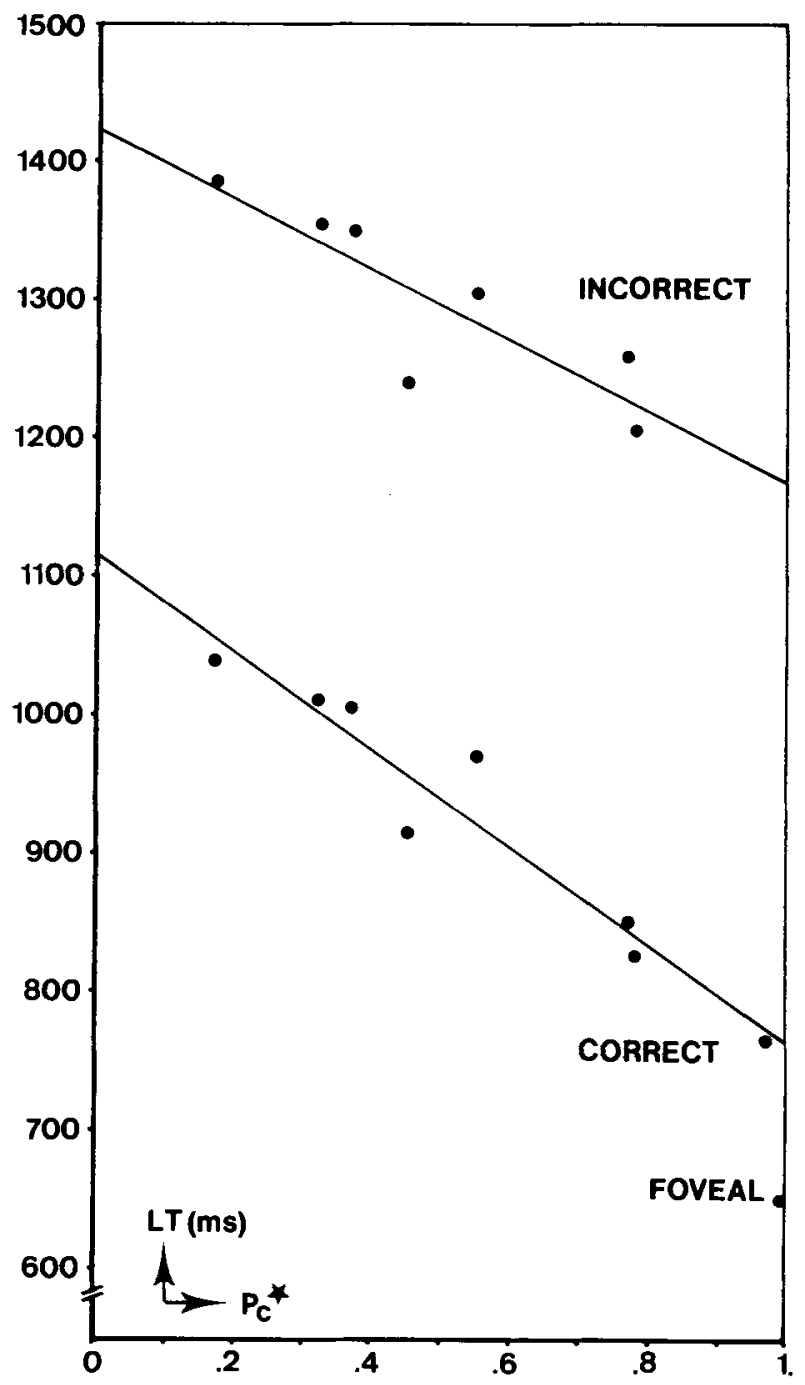

Figure 7. Response latency vs. accuracy for correct and incorrect responses. Averages over subjects, word length, and word frequency. 
showed only a marginal effect on correct responses (330 to $335 \mathrm{msec} / 100 \%$ ) and a clear shift for incorrect responses ( 445 to $255 \mathrm{msec} / 100 \%$ ). In the experiment, the subjects responded with the answer "illegible," so the right value lies somewhere in between. The high value of explained variance, namely $93 \%$ for correct $\left(r_{c}=.963\right)$ and $74 \%$ for incorrect $\left(\mathrm{r}_{\mathrm{i}}=.857\right)$ responses, rules out the possibility that correct or incorrect responses might be the result of quite different processes and again emphasizes the close relationship between scores and latencies (see also Bouwhuis, Schiepers, Schröder, \& Timmers, Note 3 ).

The probability of a correct response at eccentricities of 0 and $+1 \mathrm{deg}$ is about 1 for all word lengths. Although the recognition performance is the same, foveal latency is about $120 \mathrm{msec}$ faster (Figure 7). This facilitation may be attributed to the excess of information that is available in foveal vision. From Figures 6 and 7 and Table 2, it was reasoned that the recognition system acts as a linear integrator, and that less information produces proportionally longer latency and a larger standard deviation. This linear relationship allows an elegant interpretation of the exchangeability of information and latency. Substituting the mean foveal latency of $650 \mathrm{msec}$ (Equation 1), a probability of 1.33 is obtained for a correct response. Of course, the maximum value is 1 and the overshoot of $1 / 3$ may be interpreted as excess information reflecting the redundancy of word stimuli.

\section{GENERAL DISCUSSION}

\section{Word Recognition}

In this experiment, certain effects of word frequency, word length, and eccentricity of presentation were investigated, and both static and dynamic aspects of the word recognition process were considered. Quantitative contributions can only be elucidated in a formal word recognition model (for threeletter words, see Bouwhuis \& Bouma, 1979). We adopted the information processing approach and assumed independent contributions of perceptual and linguistic factors. A possible scheme for explaining the main visual recognition processes is illustrated in Figure 8. The additivity of information in the various stages is suggested by theoretical interpretations of Figures 6 and 7 and Table 2.

Stage 1: Activation of word concepts. Visual attributes can access word concepts directly, while linguistic factors may supply additional information. Stage 1 reflects the processor that integrates the incoming information by elevating the activation of word concepts (cf. Morton, 1969). The visual stimulation is not available at the same moment for different retinal locations, so that parafoveal informa-

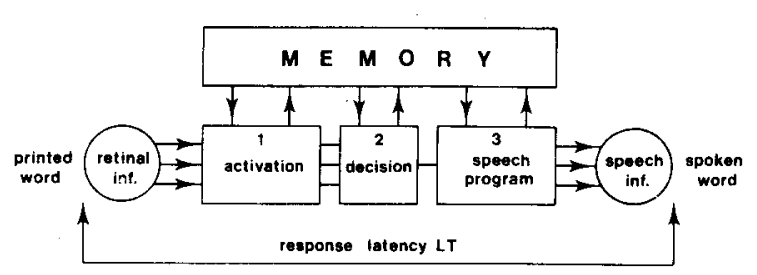

Figure 8. Word recognition scheme (for explanation see text).

tion arrives $90 \mathrm{msec} / \mathrm{deg}$ later than foveal information. The amount of incoming information is decisive, causing longer buildup times for activation in the case of low stimulation.

Stage 2: Decision between alternative responses. When the activation of a word concept exceeds a certain threshold, this word becomes available. The presence of sufficient information normally favors one concept, and the subject responds with the correct word. In case of little or obscure information, more concepts are activated (including the correct one), the alternatives have to compete, and an incorrect response will usually be produced. In this case, the contribution to correct responses will be small, and to mean correct latency negligible.

From Figure 7, it is reasoned that activation takes equal amounts of time, but decision takes an extra $400 \mathrm{msec}$ for incorrect responses. In case of too little stimulation, the response becomes "illegible." Linguistic factors exert an influence by affecting the threshold of the word concepts (Broadbent, 1967; Morton, 1969). Stage 2 determines the response quality as a function of threshold level and time: correct, 600-1,100 msec; incorrect, 1,100-1,500 msec; or illegible.

Stage 3: Speech programming. When visual recognition has been accomplished, the recognized material has to be uttered. Speech codes have to be started, including grapheme/phoneme recoding, which implies longer processing times in the case of more syllables. The voice is programmed, and, finally, a spoken word is produced.

\section{Word Recognition and Reading}

Our ultimate aim is to understand visual reading processes, and we assume that word recognition is a part of these. What does the present experiment mean as far as reading is concerned? In a previous paper (Schiepers, Note 4), a speculation was offered about the relation between successive eye fixations in reading and the integration of extracted information. On average, the visual information from a word at one saccade length to the right of the fovea arrives simultaneously with the information from the next eye fixation in which that word is in the fovea. In commenting on that experiment, Bouma (1978) wrote that "words are seen twice but read once." The present results are fully compatible with that 
hypothesis. The recognition of a word exposed at +2 deg is completed about $200 \mathrm{msec}$ later than a foveally presented word (Figure 2 ). In reading, the saccade lengths are about $2 \mathrm{deg}$ and fixations last about $200 \mathrm{msec}$. Thus, the visual information from a certain word in two successive eye fixations would exceed the recognition threshold at the same moment. Information from a word at $\mathbf{- 2}$ deg arrives no less than $400 \mathrm{msec}$ after the preceding foveal fixation of that word and may therefore possibly pass unnoticed.

Let us now explore the timing of visual information from a word in three successive eye fixations of 2 deg in length and 200 msec in duration; in the third case, the word is foveally fixated (Figure 9).

At $+4 \mathrm{deg}$, the word will be recognized after $1,050 \mathrm{msec}$ (Figure 2); $200 \mathrm{msec}$ later, in the next fixation, this word is at $+2 \mathrm{deg}$, the recognition time now being $850 \mathrm{msec}$, which, on our time scale (Figure 9), is also completed at $t=1,050 \mathrm{msec}$. Another $200 \mathrm{msec}$ later, in foveal fixation, the word needs $650 \mathrm{msec}$ to be recognized, again accomplished at $\mathrm{t}=1,050 \mathrm{msec}$. Reading experiments of McConkie and Rayner (1975) provide evidence that global attributes such as word length can be acquired from 3 to $4 \mathrm{deg}$, two saccade lengths distended from the fovea; word shape and letter specific information can be acquired from 1 to $2 \mathrm{deg}$; more peripheral information is not used. One of our main conclusions was that accuracy and latency are directly linked, implying a linear integrator model for recognition; the information from successive eye fixations is simply additive. In our example, the word information in the three successive fixations is progressively reinforced. Integration simply means addition of information and, consequently, the threshold will be exceeded earlier. The probability correct for a word at +4 and +2 deg is .3 and .75 , respectively (Figure 1), and this probability is used as an indicator for

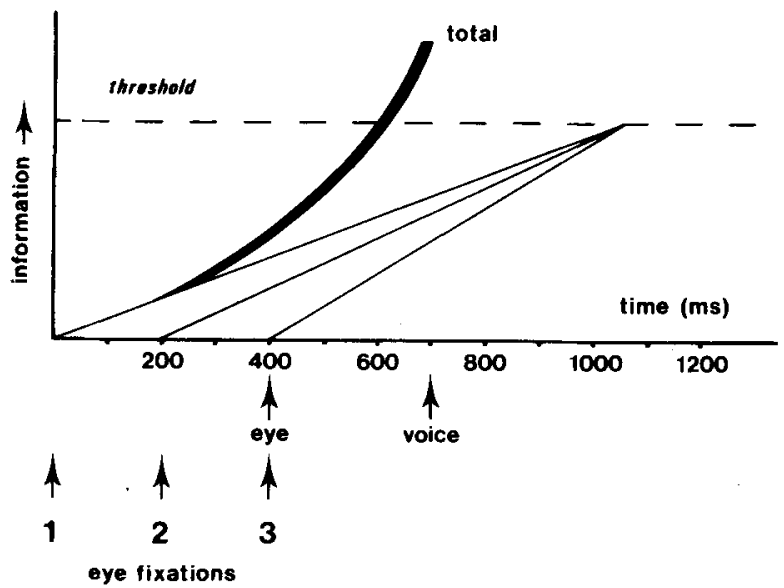

Figure 9. Time relations of the visual information in three successive eye fixations; integration results in the recognition threshold being exceeded earlier. the amount of visual information. In the linear integrator model, extra information may be directly translated into shortening of recognition time (Equation 1); for probabilities of .3 and .75, this amounts to latency differences of 100 and $250 \mathrm{msec}$, respectively. The word in the third (foveal) fixation will now be recognized after 650 (fix. 3) - 250 (fix. 2) - 100 (fix. 1) = $300 \mathrm{msec}$, speech programming included. At maximum reading speed, Bouma and de Voogd (1974) found fixation durations of 200 $300 \mathrm{msec}$ for silent reading and about $300-400 \mathrm{msec}$ for oral reading. The difference is for speech programming (Figure 8) and may be estimated at $100 \mathrm{msec} /$ fixation. Therefore, visual recognition in our example lasts for at least about $200 \mathrm{msec}$, which agrees with the limit of silent reading (Bouma \& de Voogd, 1974; McConkie \& Rayner, 1975).

Lengthening of the fixation duration means slowing down recognition, for the additive component of the following fixation is delayed. Of course, the question of how long stimulation continues is also important. Rayner (1975) suggested that the information from two fixations is brought together in a single representation of the stimulus. In our scheme (Figure 9), two fixations allow visual recognition to be completed after about $300 \mathrm{msec}$. However, comprehensive reading is possible at higher speed, but then information of more fixations is required. Since the information concerns the same words, Rayner's suggestion about the creation of a new representation seems superfluous.

Experiments of McConkey and Zola (1979) on reading text in alternating case showed that changing the letter case during the saccade was not perceived. They concluded that apparently the visual features are not integrated across fixations. This conclusion was arrived at on the basis of their matching hypothesis between fixations in reading. If the visual attributes just serve as activation for internal word concepts (cf. Gibson, 1971; LaBerge \& Samuels, 1974; Morton, 1969), their experiments suggest that the earlier parafoveal information and the present foveal information combine at the level of the internal visual word concept.

Rayner (1975) found an increase in fixation durations when a critical word was changed in a position where the eyes were approached less than 1 deg left of that word. This finding fits in quite well with our scheme: changing the word provides conflicting visual information, and recognition needs more time. His finding that a preceding saccade of 4-deg length does not affect the duration of fixation on the critical word is also understandable with processing latencies; a word at 4 deg takes $1,050 \mathrm{msec}$, the next eye fixation plus foveal recognition takes $200+650=850 \mathrm{msec}$, so the visual information of the foveal fixation predominates.

The above computations are based on single word recognition. In reading, many words are present and backward masking may occur, so the situation becomes 
even more complicated. The functional field of vision

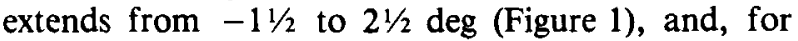
shorter words, Bouma (1978) calculated about $5 \mathrm{deg}$. In oral and silent reading, Bouma and de Voogd (1974) found a functional field of 4-5 deg; McConkey and Rayner (1975) found that the field extended to about $2 \frac{1}{2} \mathrm{deg}$ in the RVF. McConkey and Rayner (1976) stressed the asymmetry of the perceptual span in reading, which extended no further than about $1 \mathrm{deg}$ to the left of fixation. Despite more interference from adjacent words and backward masking, the functional field in reading equals that of single words. Evidently, context effects supply additional information (see also Bouwhuis, 1978).

The incorrect responses are about $400 \mathrm{msec}$ slower than correct ones, obviously because of insufficient information. This has important consequences for the regressive eye saccades that are thought to occur on the basis of conflicting recognitions or linguistic incongruence. Evidently, these are programmed much later than the actual fixation of the word, too late for readjusting control. However, the control of eye saccades in reading remains an unsolved question (Bouma \& de Voogd, 1974; Rayner \& McConkie, 1976; Shebilske, 1975).

What is the relationship between eye and voice in reading? In oral reading, the voice keeps behind the eyes and there is an eye-voice span which is far from constant, generally $1 / 2-1$ sec or $2-5$ words (Morton, 1964; Woodworth, 1938). Strictly speaking, the foveal latency of $650 \mathrm{msec}$ is the eye-voice span for a single presentation. By integration of information, oral responses in reading become quicker and take at least a latency of $300 \mathrm{msec}$ (see example), which agrees with the minimum eye-voice span of Buswell (in Woodworth, 1938). Normally, the span will be greater and will contain about 4 or 5 words. In case of confusions, recognition is tardy and a regressive eye movement may be necessary, but the flexibility of the eye-voice span guarantees a progressive reading process.

\section{Conclusions}

The present experiment corroborates a number of findings in the literature: (1) Recognition scores for single words drop from the fovea outwards, showing a visual field asymmetry (Bouma, 1973; Mishkin \& Forgays, 1952). (2) Parafoveal presentation sharply increases response latency (Eriksen \& Schultz, 1977; Lefton \& Haber, 1974). (3) Recognition scores decrease with increasing word length in the parafovea (Gill \& McKeever, 1974; Schiepers, 1976b). (4) Response latencies for foveally presented single words do not show an influence of word length (Dogget \& Richards, 1975; Johnson, 1975; Terry et al., 1976). (5) Both accuracy and latency measurements clearly show the word frequency effect, HF words having somewhat higher scores and lower latencies than LF words (Broadbent, 1967; Rosenzweig \& Postman, 1958).

In addition: (1) A principal result of this experiment was the direct coupling of accuracy and latency measurements, which showed that one variable can be predicted quite accurately by the other; this argues strongly in favor of a linearly integrating recognition system. (2) The response latencies increase with eccentricity, showing a visual field asymmetry for correct responses and none for incorrect responses. The fairly sharp increase with eccentricity cannot be ascribed to retinal factors such as acuity and convergence of nerve bundles (Eriksen \& Schultz, 1977; Rains, 1963). On average, incorrect responses were always slower than correct ones (on average $375 \mathrm{msec}$ ); for the eccentricities used, there was no overlap on the time axis (see Figure 7). (3) Proportion correct and response latency correct are not affected by word length proper, for all eccentricities. Response latency for incorrect responses shows a clear-cut influence of word length.

\section{REFERENCE NOTES}

1. Linschoten, J. De la Court's frekwentietelling van Nederlandse woorden (Report No. 6301). Utrecht: Psychology Laboratory, 1963.

2. Schröder, U. O. A controlled voice switch. Instituut voor Perceptie Onderzoek Annual Progress Report, 1977, 12, 137-139.

3. Bouwhuis, D. G., Schiepers, C. W. J., Schröder, U. O., \& Timmers, H. Temporal structure of visual word recognition responses. Instituut voor Perceptie Onderzoek Annual Progress Report, 1978, 13, 83-93.

4. Schiepers, C. W. J. Response latencies in parafoveal word recognition. Instituut voor Perceptie Onderzoek Annual Progress Report, 1974, 9, 99-103.

\section{REFERENCES}

Bouma, H. Interaction effects in parafoveal letter recognition. Nature, 1970, 226, 177-178.

Bouma, H. Visual recognition of isolated lower case letters. Vision Research, 1971, 11, 459-474.

Bouma, H. Visual interference in the parafoveal recognition of initial and final letters of words. Vision Research, 1973, 13, 767-782.

Bouma, H. Visual search and reading: Eye movements and functional visual field. In Proceedings of the 7th International Symposium on Attention and Performance, Sénanque, 1976. Hillsdale, N.J: Erlbaum, 1978.

Bouma, H., \& DE VoogD, A. H. On the control of eye saccades in reading. Vision Research, 1974, 14, 273-284,

Bouwhuis, D. A model for the visual recognition of words of three letters. In J. Requin (Ed.), Attention and performance VII. Hillsdale, N.J: Erlbaum, 1978.

Bouwhuis, D. Word knowledge and letter recognition as determinants of word recognition. In P. A. Kolers, M. Wrolstad, \& H. Bouma (Eds.), Processing of visual language I. New York: Plenum, 1979.

Bouwhuis, D., \& Bouma, H. Visual word recognition of threeletter words as derived from the recognition of the constituent letters. Perception \& Psychophysics, 1979, 25, 12-22.

Broadbent, D. E. Word frequency effect and response bias. Psychological Review, 1967, 74, 1-15. 
Cosky, M. J. The role of letter recognition in word recognition. Memory \& Cognition, 1976, 4, 207-214.

DoggeTt, D., \& Richards, L. G. A reexamination of the effect of word length on recognition thresholds. American Journal of Psychology, 1975, 88, 583-594.

Erikgen, C. W., \& Hoffman, J. E. Some characteristics of selective attention in visual perception determined by vocal reaction time. Perception \& Psychophysics, 1972, 11, 169-171.

Eriksen, C. W., \& Schultz, D. W. Retinal locus and acuity in visual information processing. Bulletin of the Psychonomic Society, 1977, 9, 81-84.

Eriksen, C. W., Pollack, M. D., \& Mon'tague, W. E. Implicit speech: Mechanism in perceptual encoding? Journal of Experimental Psychology, 1970, 84, 502-507.

Estes, W. K. The locus of inferential and perceptual processes in letter identification. Journal of Experimental Psychology: General, 1975, 2, 122-145.

Gibson, E. J. Perceptual learning and the theory of word perception. Cognitive Psychology, 1971, 2, 351-368.

Ginson, E. J., \& LEvin, H. The psychology of reading. Cambridge: M.I.T. Press, 1975.

Gill, K. M., \& McKeEver, W. F. Word length and exposure time effects on the recognition of bilaterally presented words. Bulletin of the Psychonomic Society, 1974, 4, 173-175.

Johnson, N. F. On the function of letters in word identification: Some data and a preliminary model. Journal of Verbal Learning and Verbal Behavior, 1975, 14, 17-29.

Kole Rs, P. A. Three stages of reading. In H. Levin \& J. P. Williams (Eds.), Basic studies in reading. New York: Basic Books, 1970.

LABERge, D., \& Samuels, S. J. Toward a theory of automatic information processing in reading. Cognitive Psychology, 1974, 6, 293-323.

Lefton, L. A., \& Haber, R. N. Information extraction from different retinal locations. Journal of Experimental Psychology, $1974,102,975-980$.

McConkey, G. W., \& Rayner, K. The span of the effective stimulus during a fixation in reading. Perception \& Psychophysics, 1975, 17, 578-586.

McConkey, G. W., \& Rayner, K. Asymmetry of the perceptual span in reading. Bulletin of the Psychonomic Society, 1976, 8, 365-368.

McConkey, G. W., \& ZolA, D. Is visual information integrated across successive fixations in reading? Perception \& Psychophysics, 1979, 25, 221-224.

McNemar, W. Psychological statistics (3rd ed.). New York: Wiley, 1963.

Mishrin, M., \& Forgays, D. G. Word recognition as a function of retinal locus. Journal of Experimental Psychology, 1952, 43, 43-48.

Morton, J. The effect of context upon speed of reading, eye movements and eye voice span. Quarterly Journal of Experimental Psychology, 1964, 16, 340-354.

MorTon, J. Interaction of information in word recognition. Psychological Review, 1969, 76, 165-178.

Neisser, U. Cognitive Psychology. New York: Appleton-CenturyCrofts, 1967.

RAINS, J. D. Signal luminance and position effects in human reaction time. Vision Research, 1963, 3, 239-251.

RAYNER, $K$. The perceptual span and peripheral cues in reading. Cognitive Psychology, 1975, 7, 65-81.

RAYNeR, K., \& McConkie, G. W. What guides a reader's eye movements? Vision Research, 1976, 16, 829-837.

Rosenzweig, M. R., \& Postman, L. Frequency of usage and the perception of words. Science, 1958, 127, 263-266.

SCHIE PE RS, C. W. J. Global attributes in visual word recognition. Part 1: Length perception of letter strings. Vision Research, 1976, 16, 1343-1349. (a)

SCHIEPE RS, C. W. J. Global attributes in visual word recognition. Part 2: The contribution of word length. Vision Research, 1976, 16, 1445-1454. (b)

Schie PERS, C. W. J. Global attributes in visual word recognition. Unpublished doctoral thesis, University of Nijmegen, 1976. (c)

SCHIE PE RS, C. W. J. Global attributes in visual word recognition: Contour perception of three-letter strings. Acta Psychologica, $1978,42,205-223$.

Shebilske, W. Reading eye movements from an information processing point of view. In D. W. Massaro (Ed.), Understandlanguage. New York: Academic Press, 1975.

Terry, P., Samuels, S. J., \& LaBerge, D. The effects of letter degradation and letter spacing on word recognition. Journal of Verbal Learning and Verbal Behavior, 1976, 15, 577-585.

UIT DEN BOOgAART, P. C. Woordfrequenties in geschreven en gesproken Nederlands. Utrecht: Oosthoek/Scheltema en Holkema, 1975.

Wheeler, D. Processes in word recognition. Cognitive Psychology, 1970, 1, 59-85.

Woodworth, R. S. Experimental Psychology. New York: Holt, 1938.

\section{NOTE}

1. LaBerge and Samuels (1974) suggested that a shift of attention takes time, at least for complex stimuli. If this attention shift required more time for increased parafoveal position, it could have been a component of the LT $-\phi$ slope. However, we have the impression that the subjects have their attention directed both left and right at the expected position of the stimulus.

(Received for publication July 23, 1979; revision accepted October $18,1979$. 